\title{
Mathematical models of changes in the surface layer of frictional pairs as a tool to optimize the wear process
}

Maciej Matuszewski ${ }^{1, *}$, Małgorzata Słomion ${ }^{1}$, Adam Mazurkiewicz ${ }^{1}$ and Danil Yu. Pimenov $^{2}$

${ }^{1}$ University of Science and Technology in Bydgoszcz, Faculty of Mechanical Engineering, 85-796 Bydgoszcz, Poland

${ }^{2}$ South Ural State University, Department of Automated Mechanical Engineering, Lenin Prosp. 76, Chelyabinsk 454080, Russia

\begin{abstract}
The paper presents mathematical models developed on the experimental studies whose purpose to determine the relationship between studied factors and changes occurring in the surface layer. Developed polynomials allowed to determine expected changes appearing under the influence of external forces in the surface layer of working elements as a kinematic pair with a conformal contact. Therefore, it is possible to control the operation process to minimize changes in the surface layer, so the structural features of kinematic pair stay unchanged in the entire period of work.
\end{abstract}

\section{Introduction}

\subsection{Condition of the surface layer}

The surface layer is defined as the outer part of the material layer, which is characterized by a compound stereometric structure. Its condition meaningly determines the functional features of cooperating elements such as durability or reliability and affects the wear process due to tribological processes occurring in this layer which lead to wear and damage [1-4].

Functional qualities of machines are the function of the surface layer parameters which are the result of industrial processing and operation. Factors such as durability of machine elements and reliability of technical object should be possible to describe by means of characteristics of the surface layer kinematic pair elements involved in the friction process, including external factors. Then condition of the object can be assessed and occurrence can be predicted of damage. These assignments are the basis of technical diagnostics activities and they are diagnosing and forecasting, respectively. Their aim is to tasks functional qualities of machines and devices, by enabling the control of durability and reliability features $[1,5-8]$.

Properties of the surface layer condition are determined by a set of characteristics which can be describe by a physicochemical, stereometric and stereo-physicochemical parameters. The basic ones are parameters describing the stereometric structure of the surface called surface geometrical structure, which consists of surface irregularities caused by the machining and wear processes. Deployment of distinctive geometric surface structure elements gives it anisotropic or isotropic character. Surface roughness, directionality of machining marks, waviness and surface structure defects are assumed to be the basic group of parameters describing the geometric surface structure. Physicochemical parameters include the quantities described by structural, mechanical, physical, chemical, magnetic and

*Corresponding author: matus@utp.edu.pl 
electrical features. Stereometric and physicochemical parameters include energy, surface tension, emissivity and reflection. These quantities specified for each parameter group, are relevant to operation process to a different quantities degree [2, 9-10].

Considering the tribological characteristics of the elements of friction pairs, the crucial quantities describing the surface layer condition, among the stereometric parameters, are roughness and directionality, while for the physicochemical type of material these are structure, internal stresses and hardness [10-11].

Due to the changes occuring in the surface layer (most damages occurs here) of kinematic pairs and as a result of external forces, the mathematical models were developed which aim is to detremine these changes, predict and controll the course of wear process. Weight loss, changes in the linear dimensions and selected roughness parameters were assumed to be the measure of wear. The models were developed on the basis of experimental tests to be in which the input quantities were parameters denoting the surface geometrical structure and external forces described in the following parts.

\subsection{Transformation of the technological surface layer}

As a result of various external forces, the condition of the surface layer determined by a set of manufacturing features in all phases of the machine elements existance undergoes constant changes. In case of production, these external forces are kinematic, technological parameters and machining environment. The condition of the surface layer changes practically after each technological activity and this process defines the transformation of the technological surface layer. The end of the last technological process operation of the technological process is the stage of the changes where the surface layer condition determines functional features of the kinematic pair elements and the character becomes static [12-14].

Initial the operation of a technical object, that is, the beginning of external forces impact on the machine and its components causes transformation of the technological surface layer into the operation surface layer and the process of its transformation begins. As the numerous research shows [3, 4, 13, 15] course of transformation depends on characteristics of the technological surface layer, i.e. wear process.

\subsection{Operational surface layer}

Condition of the operational surface layer should be characterized by the ability to reduce the effects of the external forces $[6,16]$.

Wear elements of kinematic pairs are defined by the process of adverse changes in the properties of the surface layer. These changes arise from cooperating elements surfaces forming kinematic pairs and can be intensified by the workplace. Evaluation of the intensity values of wear is carried out by absolute or relative measures. Volume or mass of the material separated from the surface layer of the element or thickness of the deformed or separated part of the surface layer is a measure of wear. Whereas the relative measure of wear is its intensity, which is the reference of the volume, mass or linear loss to time, friction distance or friction operation. Constant value of intensity in time characterizes the process as stabilized but when the intensity is variable, the process is unstable. Thea im is to stabilize the wear processes course by shortening the period of run in of elements, extend of the stabilized operation and eliminate an increase in the wear intensity which leads to a rapid damage growth $[6,17,18]$.

Types of tribological wear include: fatigue wear, abrasive wear, oxidation, whereas in the non-tribological wear include the effects of corrosive and erosive processes are assumed. Tribological wear is the result of cooperation of kinematic pair elements that rub each other. It is understood as the process of destroying and removing material from the 
solids surface as the result of friction which reflects continuous changes of macro and micro-dimensions and the shape of friction elements $[18,19]$.

\section{Methodologies}

The aim of the studies was to develop mathematical models based on the results of experimental tests, which allowed to determine the relationship between the studied factors and changes occurring in the surface layer.

Specimens made of $102 \mathrm{Cr} 6$ steel and a counter-specimen made of X210Cr12 steel were used for the tests. Specimens were tested on a designed triblogical stand, made at the Faculty of Mechanical Engineering of the University of Science and Technology in Bydgoszcz.

Selected values describing the surface geometrical structure (selected roughness parameters and angles of cooperation resulting from structure directivity), external forces (variable load values and relative velocity) and the qualification status of the specimens material were assumed as a set of input factors. The direct parameters characterizing the process of wear were assumed as output factors, i.e. the mass $(\Delta \mathrm{m})$ and linear $(\Delta l)$ losses and quantities describing the surface geometrical structure changes for which the following roughness parameters were selected: amplitude parameters $R q, R t$ and the parameter characterizing load capacity curve $R p k$.

$R q$ parameter (RMS roughness - root mean square profile) is associated with a commonly used $R a$ parameter (roughness average - arithmetic mean of the profile) in industrial practice and it constitues its square deviation which is the equivalent of standard deviation $\sigma$ of this parameter used in statistics. Therefore, from the cognitive point a better view is $R q$ parameter for studies. Paramters $R t$ (maximum height of the profile) and $R p k$ (reduced peak height of the profile) were chosen because of their usefulness in the characteristic of surface changes in the initial period of cooperation. Parameters were selected on the basis of an analysis of the research problem.

The following hardnesses of the specimens $H: 30,40,50 \pm 2 \mathrm{HRC}$ and for the counterspecimen $60 \pm 2 \mathrm{HRC}$ were used for the tests. As a result changes concerned mainly the surface layer of the specimens. L-AN68 machine oil was used as a lubricant for working samples. Cooperation of the samples was carried out with the following values of operation quantities:

- average speed of relative motion $(v)$ was 1,$8 ; 4,2$ i $8,4 \mathrm{~m} / \mathrm{min}$, which was respectively equivalent: 0,$03 ; 0,07$ and $0,14 \mathrm{~m} / \mathrm{s}$,

- normal loads of cooperating surfaces $(F)$ was: 300,450 i $600 \mathrm{~N}$, which corresponded to theoretical pressure in contact zone, respectively: $1 ; 1,5 \mathrm{i} 2 \mathrm{MPa}$.

Measures of changes in the surface layer were done for the following values of angles cooperation $(\alpha)$ resulting from association of structure directivity trace on samples and counter-sample: $0^{\circ}, 30^{\circ}, 45^{\circ}, 60^{\circ}, 90^{\circ}$ and on the following friction roads: $(L): 100,200$, $300,400,500$ i $600 \mathrm{~m}$.

On the basis of analysis of the carried out tests, the literature information that refers to mechanism of wear has been confirmed, i.e. the most intense changes are always observed at the beginning of the cooperation and after this period stabilization follows. It was also shown that the angle beetween characteristic directionality of the related surfaces affects surface layer changes and the biggest modifications are noticed for angle $\alpha=0^{\circ}$ and the smallest for angle $\alpha=90^{\circ}$. The characteristic of the discussed changes were demonstrated for each of the examined quantity $(m, l, R q)$ accepted for a description of changes in the surface layer condition.

The impact on external forces of the surface layer condition changes was confirmed as well. 


\section{Mathematical models of changes in the surface layer}

The experimental studies show a small influence of relative velocity $(v)$ therefore, this factor was not included in the developed mathematical models, hence, the model will be a function of four independent variables: $\alpha, F, H, L$. Three mathematical models were accepted for the analysis. The most accurate choice was based on a statistical analysis and comparison. These models are a function of four variables and are based on a linear function, a linear function with interactions and a quadratic function.

Factors of regression equations were estimated in the assumed form in order to determine set the dependence of the examined quantities for the accepted input factors. On the basis of t-Student's statistics $(\alpha=0,005)$ and including only significant factors, the models assumed the following form:

$$
\begin{aligned}
& \Delta m=6,887+0,014944 H_{k} \\
& \Delta l=9,558+0,000013 F_{j}+0,000242 H_{k} \\
& \Delta R q=1,494+0,001752 \alpha_{i}-0,00074 F_{j}+0,006314 H_{k}-0,000806 L_{n} \\
& \Delta R t=9,193+0,011064 \alpha_{i}-0,002999 F_{j}+0,013157 H_{k}-0,003673 L_{n} \\
& \Delta R p k=1,03+0,001653 \alpha_{i}-0,000399 F_{j}+0,007857 H_{k}-0,000678 L_{n}
\end{aligned}
$$

Then the patterns were expanded for subsequent models and on the basis of t-Student's statistics only statistically significant factors were included:

1. Model of linear function with interactions:

$$
\begin{aligned}
& \Delta m=6,897+14,743 \cdot 10^{-3} H_{k} \\
& \Delta l=9,564-0,345 \cdot 10^{-3} \alpha_{i}+0,17 \cdot 10^{-6} \alpha_{i} F_{j} \\
& \Delta R q=1,575-10,4 \cdot 10^{-6} F_{j}-3,3614 \cdot 10^{-6} L_{n}+11,3 \cdot 10^{-9} \alpha_{i} L_{n}+ \\
& -5,99 \cdot 10^{-9} F_{j} L_{n}+85,2 \cdot 10^{-9} H_{k} L_{n} \\
& \Delta R t=9,575-0,345 \cdot 10^{-3} \alpha_{i}-10,4 \cdot 10^{-6} F_{j}-3,3614 \cdot 10^{-6} L_{n}+ \\
& +5,38 \cdot 10^{-6} \alpha_{i} H_{k}-0,149 \cdot 10^{-6} F_{j} H_{k}-5,99 \cdot 10^{-9} F_{j} L_{n} \\
& \Delta R p k=1,097-0,345 \cdot 10^{-3} \alpha_{i}-3,3614 \cdot 10^{-6} L_{n}+11,3 \cdot 10^{-9} \alpha_{i} L_{n}+ \\
& -5,99 \cdot 10^{-9} F_{j} L_{n}+85,2 \cdot 10^{-9} H_{k} L_{n}
\end{aligned}
$$

2. Model of quadratic function:

$$
\begin{aligned}
& \Delta m=4,649-223,847 \cdot 10^{-6} \alpha_{i}+132,619 \cdot 10^{-3} H_{k}+5,38214 \cdot 10^{-6} \alpha_{i} H_{k}+ \\
& -1,34215 \cdot 10^{-6} \alpha_{i}^{2}-1,473443 \cdot 10^{-3} H_{k}^{2} \\
& \Delta l=9,511+2,174548 \cdot 10^{-3} H_{k}+425,45 \cdot 10^{-9} \alpha_{i} F_{j}
\end{aligned}
$$




$$
\begin{aligned}
& \Delta R q=1,578-2,353056 \cdot 10^{-3} L_{n}+2,90476 \cdot 10^{-6} \alpha_{i} F_{j}+ \\
& -42,9365 \cdot 10^{-6} \alpha_{i} H_{k}+3,68254 \cdot 10^{-6} \alpha_{i} L_{n}-14,881 \cdot 10^{-6} F_{j} L_{n}+ \\
& +14,2976 \cdot 10^{-6} H_{k} L_{n}+2,46508 \cdot 10^{-6} L_{n}^{2} \\
& \Delta R t=10,892+39,424565 \cdot 10^{-3} \alpha_{i}-5,660397 \cdot 10^{-3} F_{j}-10,946706 \cdot 10^{-3} L_{n}+ \\
& -605,079 \cdot 10^{-6} \alpha_{i} H_{k}+11,1746 \cdot 10^{-6} \alpha_{i} L_{n}+93,4286 \cdot 10^{-6} F_{j} H_{k}+ \\
& -5,09603 \cdot 10^{-6} F_{j} L_{n}+37,369 \cdot 10^{-6} H_{k} L_{n}+12,6156 \cdot 10^{-6} L_{n}^{2} \\
& \Delta R p k=0,991+2,035072 \cdot 10^{-3} \alpha_{i}+13,932143 \cdot 10^{-3} H_{k}-2,210595 \cdot 10^{-3} L_{n}+ \\
& -31,9841 \cdot 10^{-6} \alpha_{i} H_{k}+2,99206 \cdot 10^{-6} \alpha_{i} L_{n}-917,46 \cdot 10^{-9} F_{j} L_{n}+ \\
& +17,2143 \cdot 10^{-6} H_{k} L_{n}-125,714 \cdot 10^{-6} H_{k}^{2}+1,87116 \cdot 10^{-6} L_{n}^{2}
\end{aligned}
$$

The estimated empirical models reflect changes registered in experimental studies. For the received and statistically developed mathematical models the following statistical calculations and analysis of variance were determined: the coefficient of multiple correlation $(R)$, standard error of the regression $(s)$ the Fisher-Snedecor distribution $(F)$ regression for the significance level of the test $\alpha=0,005$ and $95 \%$ quantile of the FSnedecor distribution $\left(F_{t a b}.\right)$. Table 1 summarizes the statistics of regression and analysis of variance for the accepted models.

Table 1. Results of statistical calculations and analysis of variance.

\begin{tabular}{|c|c|c|c|c|c|}
\hline & $R$ & $S$ & $F$ & $F_{\text {tab. }}$ & $F / F_{\text {tab. }}$ \\
\hline \multicolumn{7}{|c|}{ The results of statistical calculations for the linear function } \\
\hline$\Delta m$ & 0,8678 & 0,0704 & 236,432 & 2,40 & 98,513 \\
\hline$\Delta l$ & 0,2558 & 0,0105 & 5,424 & 2,40 & 2,26 \\
\hline$\Delta R q$ & 0,8655 & 0,1161 & 231,386 & 2,40 & 96,411 \\
\hline$\Delta R t$ & 0,7906 & 0,6967 & 129,192 & 2,40 & 53,83 \\
\hline$\Delta R p k$ & 0,8792 & 0,0903 & 263,905 & 2,40 & 109,96 \\
\hline \multicolumn{7}{|c|}{ The results of statistical calculations for the linear function with interactions } \\
\hline$\Delta m$ & 0,8679 & 0,0711 & 92,797 & 1,86 & 49,891 \\
\hline$\Delta l$ & 0,307 & 0,0105 & 3,162 & 1,86 & 1,7 \\
\hline$\Delta R q$ & 0,8935 & 0,1051 & 120,363 & 1,86 & 64,711 \\
\hline$\Delta R t$ & 0,8174 & 0,6618 & 61,224 & 1,86 & 32,916 \\
\hline$\Delta R p k$ & 0,9058 & 0,0811 & 139,013 & 1,86 & 74,738 \\
\hline \multicolumn{7}{|c|}{ The results of statistical calculations for the quadratic function } \\
\hline$\Delta m$ & 0,9987 & 0,0074 & 8004,166 & 1,72 & 4653,585 \\
\hline$\Delta l$ & 0,3461 & 0,0104 & 2,917 & 1,72 & 1,696 \\
\hline$\Delta R q$ & 0,9677 & 0,0594 & 316,178 & 1,72 & 183,824 \\
\hline$\Delta R t$ & 0,9057 & 0,4902 & 97,858 & 1,72 & 56,894 \\
\hline$\Delta R p k$ & 0,9698 & 0,047 & 338,687 & 1,72 & 196,911 \\
\hline
\end{tabular}

Large values of $F / F_{t a b}$. ratio indicate that the models are significant and consistent for factors: $\Delta m, \Delta R q, \Delta R t$ i $\Delta R p k$, whereas for $\Delta l$, they are only significant. Comparison of the results analysis of statistical calculation (the coefficient of multiple correlation $R$ ) leads to the conclusion that, among the analyzed types of equations for description of changes occurring in the kinematic pair, the models in the form of second degree polynomials should be accepted. 
Figure 1 shows a comparison of the theoretical course determined by the mathematical model as a second degree polynomial with values obtained from measurements in the example of $\Delta R q$ parameter. On the basis of this comparison it can be concluded that the estimated polynomials reflect very well changes found in empirical studies.

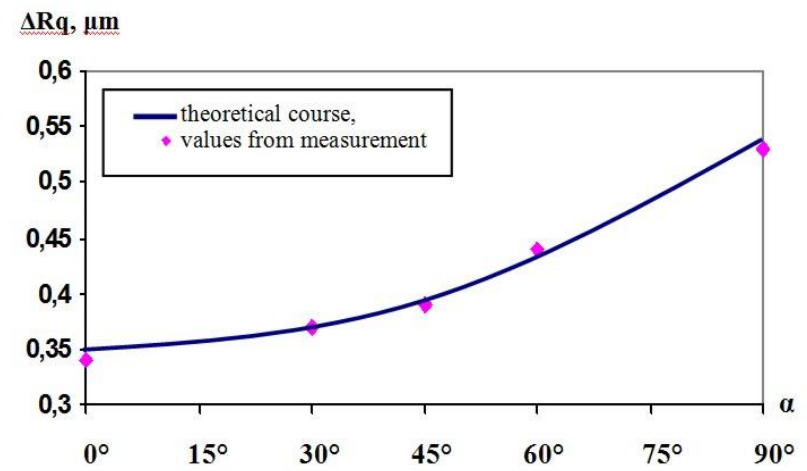

Fig. 1. Comparison of the theoretical course with values obtained from the measurements.

The presented results of theoretical analyzes concerning the relationship between the parameters describing changes in the surface layer and factors accepted as a set of input quantities, enable selection of the surface layer features for which the surface layer will be characterized by the expected functional qualities.

\section{Summary}

Statistical analysis of the correlation has shown the interdependence of the studied factors. Presented mathematical models have described the relations between tested external forces and changes in the surface layer and they can be used in forecasting the wear process of kinematic pairs with a conformal contact and also at the stage of designing (with tribological criteria) the technological process of the kinematic pair elements, including the directivity of the geometric surface structure. Especially important may be models concerning changes in the volume accepted as a measure of direct wear, i.e. changes in the linear dimension and weight loss, becouse modifications of these values below permitted limits lead to the component damage. Models that refer to changes of parameters describing the geometric surface structure can complete the information on conditions of the cooperating friction pairs elements.

\section{References}

1. B. Żółtowski, C. Cempel (edi.), Engineering diagnostics of machines (Inżynieria diagnostyki maszyn), (Publ. Institute for Sustainable Technologies, Radom, 2004)

2. M. Łukasiewicz, T. Kałaczyński, J. Musiał, J. Shalapko, Diagnostics of buggy vehicle transmission gearbox technical state based on modal vibrations. Journal of Vibroengineering, 16, 6, 3137-3145 (2014)

3. M. Matuszewski, T. Mikołajczyk, D. Yu. Pimenov, M. Styp-Rekowski, Influence of structure isotropy of machined surface on the wear process. International Journal of Advanced Manufacturing Technology, 88, 9, 2477-2483 (2017)

4. M. Styp-Rekowski, E. Mań ka, M. Matuszewski, M. Madej, D. Ozimina, Tribological problems in shaft hoist ropes wear process. Industrial Lubrication and Tribology, 67, 1, 47-51 (2015)

5. A. Bustilo, D. Yu. Pimenov, M. Matuszewski, T. Mikołajczyk, Using artificial intelligence models for the prediction of surface wear based on surface isotropy levels. Robotics and Computer Integrated Manufacturing, 53, 5, 215-227 (2018) 
6. I. M. Hutchings, Tribology. Friction and wear of engineering materials, (Elsevier, Cambridge, 1992)

7. T. Kałaczyński, M. Łukasiewicz, J. Musiał, R. Polasik, M. Szczutkowski, N. Dluhunovych, J. Wilczarska, T. Kasprowicz: Analysis of the diagnostic potential research thermovision in the technical state of combustion engine injectors assessment, 24th International Conference Engineering Mechanics 2018, Svratka, Czech Republic, Book of full texts, Institute of Theoretical and Appiled Mechanics of the Czech Academy of Sciences, Prague, 357-360 (2018)

8. Ł. Muślewski, Evaluation Method of Transport Systems Operation Quality. Polish Journal of Environmental Studies, 18, 2A, Hard Olsztyn, Olsztyn (2009)

9. T. Burakowski, The importance of surface engineering in tribology (Znaczenie inżynierii powierzchni w tribologii). Tribologia, 4, 1097-1111 (2002)

10. K. E. Oczoś, W. Lubimow, Surface geometric structure (Struktura geometryczna powierzchni), (Publ. Rzeszow University of Technology, Rzeszów, 2003)

11. J. Peters, Contribution of CIRP to the development of metrology and surface quality evaluation during the last fifty years. Annals of CIRP, 50, 471-488 (2001)

12. E. Mańka, M. Słomion, M. Matuszewski, Constructional features of ropes in functional units of mining shaft hoist. Acta Mechanica et Automatica, 12, 1, 66-71 (2018)

13. M. Matuszewski, M. Styp-Rekowski, Influence of texture direction of kinematic pair elements surfaces on service operated layer transformation. Tribologia, 4, 87-97 (2006)

14. J. Sadowski, The thermodynamic theory of friction and wear, (Publ. Radom University of Technology, Radom, 2003)

15. M. Styp-Rekowski, J. Musiał, Formation tribological features of special bearings at particular stages of engineering activity (Ksztattowanie cech tribologicznych tożysk specjalnych na poszczególnych etapach działalności inżynierskiej). Tribologia, 5-6, 921-928 (1997)

16. Ł. Muślewski, M. Pająk, B. Landowski, B. Żółtowski, A method for determining the usability potential of ship steam boilers. Polish Maritime Research, 4 (92), 23, 105-111 (2016)

17. G. W. Stachowiak, A. W. Batchelor, Engineering tribology, (Butterworth-Heinemann, Great Britain, 2001)

18. J. Williams, Engineering tribology, (Cambridge University Press, Cambridge, 2005)

19. Z. Lawrowski, Tribology: friction, wear and lubrication (Tribologia: tarcie, zużywanie i smarowanie), (PWN, Warszawa, 1993) 